\title{
10 Online learning for older persons during the COVID-19 pandemic in Malta
}

\author{
The good, the bad, and the ugly
}

\author{
Marvin Formosa
}

The chapter reports on a qualitative research study at the University of the Third Age (U3A) in Malta which, during the COVID-19 pandemic, ceased all its classroom-based education, and adopted an online learning strategy. The aim of the research investigation consisted in exploring the positive and negative impacts of the change in this mode of teaching and learning on U3A members. On one hand, older learners relished a virtual learning environment for its flexibility potential as it allowed them to juggle jobs, family care-giving, and learning schedules without conflicting timings, re-read a lecture or take more time to reflect on some "difficult" material, and mitigating against discriminating factors such as age, physical appearance, disability, and gender. On the other hand, since this shift was not carried out under the supervision of e-learning specialists, the novel learning environment included no dynamic interaction, neither between tutors and learners, nor among learners themselves, so that the latter had no opportunity to articulate responses with as much depth and forethought as in traditional face-to-face educational situations. At the same time, the shift towards online learning faced the pressing issue of digital exclusion. This chapter concludes that the implementation of online learning in later life needs to uphold four principles of good practice: making provisions for older persons who do not have access to online services, ensuring that technology is accessible to all older persons, providing hardware and software equipment and internet access to older learners, and investing in skilling older persons in digital competencies.

\section{Introduction}

Since the identification of the first COVID-19 case in Wuhan, China, in December 2019, one witnessed a steady output of academic articles on the pandemic's wide-reaching impacts. An area that received much global attention constituted that interface between COVID-19 and later life. This was far 
from surprising since COVID-19 proved to be a very serious viral infection for persons aged 80 and over. Literature underlined the pandemic's deadly effect among frail older persons, and how nursing homes for older persons became hot incubators for the coronavirus, as more than half of all COVID-19 deaths in many countries occurred amid residents in longterm care facilities (Ayalon et al. 2020). Other research demonstrated how the COVID-19 pandemic accentuated the exclusion of and prejudice against older adults, as the health crisis led to a disturbing public discourse about ageing that questioned the value of older adults' lives and their valuable contributions to society (Previtali et al. 2020). Moreover, as most governments prohibited older persons from leaving their residences unnecessarily and barred extended family gatherings, much attention was focused on social isolation and loneliness experienced by older adults, and the resulting impact on their emotional wellbeing (Berg-Weger \& Morley 2020).

The study reported herein seeks to continue contributing to the knowledge relating to the impact of the COVID-19 health emergency situation on the quality of life and wellbeing of older persons by focusing on older adult learning - which refers to the process in which older adults, "individually and in association with others, engage in direct encounter and then purposefully reflect upon, validate, transform, give personal meaning to and seek to integrate their ways of knowing" (Mercken 2010: 9). Literature on lifelong learning lists a range of motivational factors inducing participation, but in later life most enrolment stems from the meeting of coping and expressive needs, as many older persons seek to adjust to decreasing physical and social capital, retirement, widowhood, pursuing knowledge for its own sake, and personal developments (Formosa 2019a). This chapter reports on the experiences of the University of the Third Age (U3A) in Malta which, on 12 March 2020, was legally mandated to cease all its classroom-based education, and which instantly took the decision to adopt an online learning strategy. ${ }^{1}$ It includes four sections. While the next section familiarises the reader with older adult learning and U3As in particular, the third part presents key analytic inferences regarding the beneficial, negative, and discriminatory consequences arising from this change in mode of teaching and learning. The final part puts forward a number of conclusions and also highlights recommendations for the good practice of older adult learning during emergency situations that necessitate lockdown and social distancing policies.

\section{The University of the Third Age and e-learning in later life}

Universities of the Third Age (U3As) can be loosely defined as learning centres where older persons may acquire new knowledge of significant issues, or validate the knowledge which they already possess, in an agreeable milieu and in accordance with easy and acceptable methods, with the objective of preserving their vitality and participating in the life of the community 
(Midwinter 1984). As its title postulates, the U3A's target audience are people in the third age phase of their life course. Whilst some centres put age 60 and over as a prerequisite for membership, others allow persons above the age of 50. The U3A movement has not only withstood the test of time but is also marked by an extensive increase of centres and members all over the globe (Formosa 2019b).

U3As are no exception to the e-learning revolution. Although the primary scope of initial experimentation with online courses was solely to reach out to older persons who could not join their peers in the classroom-setting, such as those living in remote areas and the homebound, this stance soon changed (Formosa 2014). As internet connection became a more common feature of daily living in later life (in New Zealand, Canada, Sweden, and the United States almost half the population aged 65-plus go online), and once the coming of the Web 2.0 internet revolution - with its Blogs, Wikis, Moodle, and Podcasts - brought the possibility for interactive learning to previously unimaginable levels, it became evident that virtual learning can provide a reliable and valid learning experience (Moreira 2016). The first international online U3A, named U3A Online, was set up in 1998 and from the outset it had a global focus by comprising learners from Australia, New Zealand and the United Kingdom who recognised the potential of the internet for harnessing the expertise of a worldwide cadre of volunteers who would provide low cost, intellectually stimulating courses and resources for a world community of learners and other volunteers (Formosa 2014). Swindell $(2000,2002)$ conducted a number of studies on possibilities and limitations of U3A Online. He found that older people, even those who live in large cities, tend to experience a sense of isolation that is often not recognised by the majority of the community. Hence, programmes such as U3A Online have the potential to make an important contribution to the wellbeing of those older persons who experience an increasing sense of isolation with age despite their living in seemingly well serviced and well-resourced communities. This overall feeling was summed up by different learners:

Many thanks to you for my being able to enjoy what has turned out to be the most pleasurable weeks of my life.... Thank you for the opportunity to work through this programme ... I have really enjoyed the course and I am sorry it is over. It has inspired me to push on, further afield.

online learners, cited in Swindell \& Vasella (1999: vii)

Moreover, U3A Online was credited for being a smart application of internet technology for helping to bridge the grey digital divide (Swindell et al. 2011). Yet, Swindell's $(2000,2002)$ research also underlined the mistake of not initially screening participants to determine their levels of digital competencies. Since participants were required to register and e-mail some background detail, it was assumed that they would have the necessary computer skills. This supposition was, nevertheless, incorrect for about half of 
the registrants - and especially for less educated individuals and older persons with working-class backgrounds who tend to possess lower levels of cultural capital - as during the first few weeks of the course the tutors spent many hours providing telephone and email advice to individuals about matters like saving stories as text files and attaching files to e-mails. Even when instructions were provided some confusion remained. Indeed, four and five weeks down the line a telephone survey found that many were still frustrated about their inability to handle computer-related tasks. This indicated that even older persons who are digitally literate may face serious obstacles in accessing a virtual learning programme.

Recent studies have confirmed Swindell's results as well as highlighting further barriers to virtual learning by older adults (Formosa 2019c). For instance, since decline in reading comprehension among older adults are related to vision problems rather than cognitive decline, e-learning designers must be aware of these sensory changes when designing courses. Guidelines that ensure that websites are age-friendly include using only sans serif fonts (e.g., "Arial" font), using 12- or 14-point font size, using double spaced text, using left justification, avoiding patterned backgrounds, inserting text alternatives for all graphics, and using a consistent layout throughout the website. Moreover, inappropriate sequencing of courses and course features can cause frustration since older adults engaged in face-to-face software training generally prefer an informal structure instead of a formalised, linear class structure. Other research has highlighted how games are being used in e-learning programmes (Formosa 2019d). However, since users of games are often forced to proceed rapidly, with less time for thought and contemplation, it follows that these types of designs could cause usability obstacles for some older adults given the decline in working memory in later life. Finally, mobile devices and mobile learning present another set of challenges for older adults since the small displays and tiny keyboards present major usability obstacles for those older persons with dexterity problems in their hands and fingers.

\section{The impact of COVID-19 on late-life learning in Malta}

Five days after Malta registered its first case of COVID-19 on 7 March 2020, the government announced an aggressive, "Asian-style," lockdown (Baldacchino 2020). All public servants, teachers and university lecturers, and most employees in the private sector began working "from home." All nonessential public gatherings, including church functions and sport events, were cancelled, and passenger flights in and out of the country were suspended so that Malta became totally isolated from the outside world. The only facilities exempted from such a strict lockdown included supermarkets and pharmacies. The country, one of the world's most densely populated, became strangely quiet. Traffic eased, air pollution went gone down by $50 \%$, and public spaces became deserted. ${ }^{2}$ It was in such circumstances that the 
University of Malta decreed its U3A to close its doors as from 15 March 2020. This did not come as a surprise since in the previous four weeks Malta was characterised by much wide uncertainty and anxiety towards the impending COVID-19 outbreak on the island. Indeed, during the previous week the number of participants had dwindled substantially, and there were constant phone calls asking whether it was safe to turn up for classes.

Following a number of virtual meetings, a decision was taken to shift all teaching and learning through the University's radio and online platforms, as from 20 April 2020. Tutors were asked to choose whether they wished to transmit their lecture via a radio broadcast or as a recorded lecture to be conveyed via an online link. While about one third of facilitators declined to participate in this new format, a decision which was fully respected, the remaining two thirds opted for radio broadcasting and online delivery in relatively equal numbers. Initially, the University asked tutors to conduct the lectures "live" during the exact scheduling of the actual sessions, but this was found not to be possible due to the closure of primary schools, as this meant that many were suddenly borne with constant parent and grandparent care during mornings. Indeed, it is worth mentioning that even those tutors who opted to transmit their lecture via a radio broadcast had to record their session at home and send to the radio station via email attachment due to the enforced lockdown. All lectures, even the ones broadcasted via the radio, remained available on the U3A's website until the end of July 2020.

\section{The good}

Older learners at the Maltese U3A had always resisted any attempt by the University to instil a virtual learning environment. In fact, when members were asked what they gain most from their involvement in U3A activities, the first thing that they usually reported was not related to the learning activities per se but the associated social outcomes such as socialising, making new friends, having the opportunity to achieve personal growth, and finding a support group which helps them through difficult periods in their personal life. However, it was positive to note that this time around the U3A members understood fully the necessity and logic for going virtual, and even applauded the U3A for providing them with alternative learning mediums rather than simply closing the classrooms. In their own words,

I was never in favour of online learning and never will be. Yet, given the circumstances, this was the right decision. I thank the U3A for having gone into such trouble. I am sure that it was not easy, but it was the right thing to do, and we are benefitting from it.

male U3A member, 67 years old

Learning via the computer or the radio is not ideal, but it is better than nothing, and the U3A is trying its utmost, we appreciate that, the most 
important thing is that we are not left idling away, staring aimlessly into space, especially when we are locked down.

female U3A member, 69 years old

They also commented that this new form of teaching and learning regaled them with much needed flexibility. They highlighted how accessing the lectures via either the radio or internet allowed them to participate in high-quality learning opportunities at their convenience which allowed them to juggle jobs, family caregiving, physical activity, and learning schedules without conflicting timings. As some learners claimed,

This is very convenient. As it stands now, with all the lectures available on the internet, I do not have to plan my life around the opening times of the U3A. Rather, I can now decide which two hours best suit my learning interests.

female U3A member, 71 years old

I admit that there are many advantages of having all the lectures available at a click of the mouse. I wake up very early in the morning and I can now use this time productively. I choose at what time I learn. This is very good. I lead a very busy life.

male U3A member, 65 years old

Many celebrated the fact that now they had the opportunity to reread a lecture or take more time to reflect on some "difficult" material before moving on to the next lecture. Interestingly, some learners enjoyed the anonymity that online learning provides. They claimed that discriminating factors such as age, physical appearance, disability, and gender became largely absent, and instead, the focus of attention was clearly on the content of the studyunit and the individual's ability to contribute thoughtfully to the material at hand. As some emphasised,

The best thing about all this is that you can listen to the lectures more than once. Sometimes, I do not always understand what the tutor is trying to explain, and need some time for the information to sink in, this is splendid for me.

female U3A member, 73 years old

Listening to the lectures is beneficial because you do not lose time going to the venue. I am also very self-conscious and feel anxious in large groups. I feel much more comfortable learning over the internet. My favourite teacher is youtube [laughing].

female U3A member, 68 years old

Finally, respondents stated that while at first it was a much tougher challenge accessing the lectures, rather than just turning up in the classroom and sitting 
passively listening to the tutor, in the long run such an experience enabled them to reach higher levels of digital competence and creativity. This occurred as they mastered the location of the right radio channel and understanding how internet links work, learning how to navigate online platforms, and sending emails to either the U3A's administration, tutors or classroom members:

They say that "necessity is the mother of invention," and it is true. I could not figure how to use the internet or send an email just a few weeks ago. Now, look at me! I manage to do all that is required from me. I feel good. I feel in touch with [the year] 2020.

male U3A member, 73 years old

It is thus clear that online learning has the potential to boost older persons' self-esteem and locus of control as they mitigate against the old adage that "old dogs cannot learn new tricks."

\section{The bad}

Despite the positive responses appraised in the previous section, it was clear that the shift towards embedding the U3A in an online learning programme was, at best, only a "work-in-progress." Indeed, older learners highlighted a number of barriers and obstacles that served to hinder an optimal learning experience. The one-way channels of radio and online transmissions resulted in no dynamic interaction between tutors and learners, and among the learners themselves. Within such an online synchronous discussion structure, the learners were not able to reflect and assert themselves on comments made by the tutor, or fellow learners, before the tutor moved on to the next item on the educational agenda. Hence, learners had no opportunity to articulate responses with much as much depth and forethought as in a traditional face-to-face educational situation:

This mode of learning provides you with no opportunity to add to the lecture or to ask a question. We have so many interesting discussions when we meet physically in class but now it is like watching a television programme.

female U3A member, 64 years old

We have always been told that our life experience enables us not only to participate in the learning taking place but also contribute. All tutors tell us how much they not only enjoy this experience but that they also learn a lot from us during the course of the discussion. This is all impossible now.

female U3A member, 68 years old

Moreover, respondents pointed out that at most times they found it difficult to be motivated in checking in, or even to want to switch on the computer or 
radio to listen to the tutor's presentation. Many found this form of learning artificial, "extremely robotic" to cite one interviewee, devoid of the human contact and social spirit that U3As are so renowned for. While the early sessions were listened to relatively rather attentively, without ever missing a meeting, in due course it became increasingly difficult to maintain such motivation and interest as the novelty wore off and tutor's presentations became more monotonous and predictable:

I must admit that after two or three weeks, I was no longer interested in switching on either the radio or computer. I could not bring myself to listen to the tutors simply describing some subject without any interaction from learners. We have the television for that. This is not how the U3A should be! male U3A member, 63 years old

The new online learning format also meant that there was less opportunity for learners to get in touch with tutors to either ask questions or deliver comments. Although learners admitted that this could be accomplished by sending an email, such a mode of communication was not face-less and unnatural, but sometimes tutors either took long to reply or never responded at all. This was very wearisome and frustrating for some learners:

Everybody had the same complaint. The availability of tutors! You cannot reach tutors easily over the radio and the internet, especially when the sessions are recorded. Some of us do not know how to email, and some tutors were not replying to our emails. I know that it was a difficult time for everybody, but if we cannot communicate with tutors, then the whole purpose of the U3A falls apart!

female U3A member, 73 years old

An analogous issue raised by interviewees revolved around the difficulty to interact with fellow learners. Since there was no physical classroom there was no opportunity to greet and catch up with friends in a face-to-face environment, and therefore, extremely problematic to maintain old and build new social relationships. As a result, many claimed that this online learning strategy made them feel isolated from their peers, and that they felt lonely in front of either their radios or computers:

Many U3A members did not even bother to switch on the radio or computer. Many do not attend to simply listen to the lectures. Many attend the U3A to catch up with friends and even make new ones. Many become members because of the social outings. I am not saying that they do not care about the classes but that the U3A is more than an educational organisation. It is a social experience. Remember, older people need social and intellectual stimulation.

female U3A member, 69 years old - emphasis in italics 
I am sure that the intentions were good but this is very, extremely, boring. More than boring, one feels isolated in front of computers. It is true that you are given an opportunity to exercise your mind, but the U3A was never invented to exercise minds in isolation, the human touch is necessary, and with online learning this is completely missing.

male U3A member, 69 years old

Finally, it also resulted that many U3A members experienced complications in following online sessions as they had difficulties staying connected at all times, either because their internet was unreliable or slow, or due to outmoded computers. Some also had sudden malfunctions in their computer, and due to the COVID-19 health emergency situation, it was not possible to get it fixed before the finish of the academic year. This meant that when online learning is deployed, older learners may suddenly find themselves cut off from the virtual classrooms due to technological hiccups which may take weeks to be resolved without a solution in sight.

\section{The ugly}

This final sub-section focuses on specific negative factors that were relatively discriminatory and biased towards either a particular sector or all U3A members. The first point considers the issue of "equity and accessibility." Prior to the commencement of the online learning programme, the U3A neglected to launch an exploratory survey to discern how many members had access to the internet. Consequently, the shift to online learning excluded those members who had no access, whether for economic or logistic reasons, to an online network. As interviewees emphasised, this was especially a concern with respect to older women and other learners living in rural and households experiencing risk-of-poverty lifestyles. The second concern refers to the issue of "digital illiteracy and incompetency." Again, no preliminary analyses were conducted by the U3A to ascertain the extent that learners possess the minimum required level of computer knowledge to master successfully an online learning environment. Since a certain degree of technological knowledge is required to follow a virtual learning programme, many learners who did not know how to operate computers or the Internet found themselves unable to continue the learning journey:

There were a lot of assumptions being made. Most importantly, and this is where the U3A got it wrong, that everybody had access to a computer. This is not correct, there are many older persons, especially widows, who do not possess a computer.

female U3A member, 71 years old

It is true that we are living in the year 2020, where the computer and the internet is something that we take for granted. But this is not the case in 
later life. Many of my friends, I am referring to women here, computers were bought by their husbands, and they do not have access to such machines.

female U3A member, 73 years old

It was a bit too much expecting us to master the computer almost overnight with no training whatsoever. Many could not follow the lectures because they did not know how to use the computer. This highlights the urgent need for further training programmes in information and communication technology for older persons.

male U3A member, 73 years old

At the same time, the U3A did not ascertain itself whether tutors who opted to transmit their learning via the online medium were knowledgeable in virtual instruction. Since the tutors were not properly trained in online delivery and methodologies, this certainly compromised the success of virtual learning programmes, since one must ensure that tutors are able to communicate well in writing and use language before launching an online learning strategy. Most importantly, an online tutor must be able to compensate for the lack of physical presence by creating a supportive environment where all learners feel comfortable participating. Yet, interviewers stated that this was far from the case, and that a good number of tutors acted no differently than if they were presenting their material in a face-to-face classroom environment:

We expected a different teaching format than what we were used in the classroom but it was exactly same, and in some respects, even worse as it was evident that some tutors were not knowledgeable as how to use the virtual environment to their advantage. They just lectured to the camera or their laptop rather than to us. They also need training in the possibilities and limitations of teaching in a virtual learning environment. male U3A member, 69 years old

Finally, interviewees noted that as the online learning strategy took its run, it became clear that some subjects are very difficult to be taught online because a virtual medium may not permit the best suited method of instruction. For example, there is no doubt that hands-on subjects such as public speaking and photography, where physical movement and practice contribute to the achievement of the learning objectives, are best taught in a face-to-face traditional learning environment. Just because it may be technologically possible to simulate a physical learning experience in a virtual environment, this does not necessarily mean that the learning objectives and outcomes will be equally achieved. Indeed, one cannot have the same curriculum serving for both physical and virtual learning environments, since what is successful in the former arena will not always translate to a 
successful online program where learning and instructional paradigms are quite different. Whilst a hybrid teaching and learning programme represents a potential solution to this problem, this was not possible in the midst of the COVID-19 health emergency situation.

\section{For further discussion...}

Three key conclusions may be derived from this study. First, despite the fact that older learners generally resist any attempt by educational providers to shift from a face-to-face classroom environment to a virtual learning setting, in times of crises (such as the COVID-19 pandemic) they do understand and accept the necessity and logic underlying such a change of strategy. Older learners may approach virtual learning with a level of mistrust at the beginning but in due course will experience a number of benefits. Older learners relish a virtual learning environment for its flexibility potential as it allowed them to juggle jobs, family caregiving, physical activity, and learning schedules without conflicting timings, opportunity to reread a lecture or take more time to reflect on some "difficult" material before moving on to the next lecture, as well as mitigating against discriminating factors such as age, physical appearance, disability, and gender. Virtual learning also has the potential to boost older persons' levels of self-esteem and locus-of-control as they found themselves improving their mastering of the internet, email communication and online learning platforms. As Swindell (2000, 2002) found out, this research supports the benefits of e-learning environments in later life by making important contributions to the social and emotional wellbeing of older persons as it attributes them with a new sense of purpose and excitement in their lives, and helping to bridge the age digital divide by motivating older persons to reach better levels of digital competency so as to be able follow the online learning classes with profit. Indeed, engaging with peers in online and virtual learning programmes tends to foster a sense of belonging to a group, improve self-esteem, and helps address isolation and solitude among older adults.

Secondly, the shift from a face-to-face classroom environment to a virtual learning setting is neither straightforward nor simple. Unless this shift is carried out under the supervision of e-learning specialists, the learning environment may result in no dynamic interaction between tutors and learners, and among learners themselves, so that the latter will have no opportunity to articulate responses with as much depth and forethought as in a traditional face-to-face educational situation. Moreover, it may result in low of levels of motivation for potential learners to participate, especially if the tutors' presentations are no different to those portrayed in face-to-face classrooms, and if there is less opportunity for learners to get in touch with tutors to either ask questions or deliver comments. In the wrong hands, an online learning environment may actually be counterproductive to the initial aims of the U3A Online as the difficulty for learners to maintain old and 
build new social relationships may make them feel isolated from their peers and lonely in front of either their radios or computers. Moreover, this study showed that despite the two decades of experience in online learning for older persons the same mistakes continue to subsist. For instance, while the Maltese U3A failed to pre-screen participants to determine how many members had access to the internet and the extent that they possess the minimum required level of computer knowledge to master successfully an online learning environment, no attention was made to the sensory changes when designing courses so that the electronic information being sent and shared uphold the principles of age-friendly digitalisation by using fonts and colours well-defined and sharp enough for older persons.

Finally, one cannot fail to mention that any efforts to implement educational programmes during the COVID-19 pandemic through the online media, included the trial reported herein, met a range of obstacles due to the pressing issue of digital exclusion. Since the very beginning of the lockdown, the gap between those with good and available internet connection, and between those owning electronic devices and others lacking such tools (which have suddenly become essential goods), was apparent. As COVID-19 spurred many more people to use the internet in new ways compared to before the outbreak, it has also further exposed and deepened the divide between the digital haves and have nots (Ipsos MORI 2020). Indeed, many U3A members experienced complications in following online sessions as they had difficulties staying connected at all times, either because their internet was unreliable or slow, or due to outmoded computers. Some also had sudden malfunctions in their computer, and due to the COVID-19 health emergency situation, it was not possible to get it fixed before the finish of the U3A academic year. This meant that when online learning is deployed, older learners can suddenly find themselves cut off from the virtual classrooms due to technological hiccups, that may take weeks to be resolved without a solution in sight. There is no doubt that the virtual world has great potential to reduce social and economic inequalities affecting older people. However, it can also exacerbate pre-existing ones and even create new ones, and to ensure that everyone, regardless of age or ability can communicate, the virtual world must be accessible; in other words, being designed to meet the needs and abilities of as many people as possible, but perhaps especially the ageing population (International Telecommunications Union 2021).

Such conclusions demonstrate clearly the ubiquitous digital poverty in later life. While the long-standing digital divide between younger and older persons, as well as within the older cohorts themselves, has been significantly exacerbated by the pandemic, it also follows that digital inclusion is not just about being online, it is also about using the Internet skilfully and with confidence. Not only older people do not possess such expertise and self-assurance, they are also characterised by a lack of awareness among older adults of the support available. This is an ongoing challenge in digital 
exclusion and one that exacerbates digital poverty in later life (Centre for Ageing Better (2021)). To mitigate against such lacunae, this chapter recommends the following four principles of good practice for online learning in later life: (a) making provisions for older persons who are not online by ensuring that in the event of future lockdowns one finds ways of directly contacting those individuals who are not able to leave their home; (b) ensuring that technology is accessible so that hardware and software can be used by as many people as possible, regardless of environment, device being used, age, social class, gender, digital competence and/or cultural background; (c) providing equipment and internet access by working to expand access to broadband, data packages, and to computer and ICT packages, in particular for individuals and families on low incomes who are most likely to be digitally excluded; and (d), investing in skilling older persons in digital competencies since simply providing access to equipment and the Internet will not be effective if people cannot use the technology or if they see technology as a barrier (Ipsos MORI 2020).

\section{Notes}

1 The Maltese archipelago is a European Union Member State. It consists of three islands - Comino, Gozo, and Malta. Comino is uninhabited, and with Gozo having a population of 33,388 residents, leaves Malta as the major island in this archipelago state, with 460,171 residents (2018 Figures) (National Statistics Office 2020).

2 Although the lockdown was gradually lifted in June, such a far-reaching policy bore much fruit in the short term. At the time of submitting this chapter (6 July 2021), Malta had registered 30,664 COVID-19 cases and 420 COVID-related deaths, with $67 \%$ of the population fully vaccinated.

\section{References}

Ayalon, L., Zisberg, A., Cohn-Schwartz, E., Cohen-Mansfield, J., Perel-Levin, S., Bar-Asher Siegal, E. (2020). Long-term care settings in the times of COVID-19: Challenges and future directions. International Psychogeriatrics, 32 (10), p. 11239-11243.

Baldacchino, G. (2020). Coronavirus and Malta: Weathering the storm. The Round Table, 109 (3), p. 322-323.

Berg-Weger, M., Morley, J.E. (2020), Loneliness and social isolation in older adults during the covid-19 pandemic: Implications for gerontological social work. The Journal of Nutrition, Health \& Aging, 24 (5), p. 546-558.

Centre for Ageing Better (2021). Covid-19 and the digital divide. Centre for Ageing Better, London, United Kingdom. https://www.ageing-better.org.uk/sites/default/ files/2021-07/COVID-19-and-the-digital-divide.pdf

Formosa, M. (2014). Four decades of Universities of the Third Age: Past, present, and future. Ageing \& Society, 34 (1), p. 42-66.

Formosa, M. (2019a). Third age learning for active ageing: The Maltese experience. In: Formosa, M. (ed), The University of the Third Age and active ageing: European and Asian-Pacific perspectives. Springer, Cham, Switzerland, p. 91-93. 
Formosa, M. (2019b). Active ageing through lifelong learning: The University of the Third Age. In: Formosa, M. (ed), The University of the Third Age and active ageing: European and Asian-Pacific perspectives. Springer, Cham, Switzerland, p. 3-18.

Formosa, M. (2019c). Educational gerontology. In: Gu, D., Dupre, M. (eds), Encyclopedia of gerontology and population ageing. Springer, Cham, Switzerland. https://doi.org/10.1007/978-3-319-69892-2_411-1

Formosa, M. (2019d). University of the Third Age. In: Gu, D., Dupre, M. (eds), Encyclopedia of gerontology and population ageing. Springer, Cham, Switzerland. https://doi.org/10.1007/978-3-319-69892-2_412-1

International Telecommunications Union. (2021). Ageing in a digital world - from vulnerable to valuable. International Telecommunications Union, Geneva, Switzerland. https://www.itu.int/myitu/-/media/Publications/2021-Publications/Ageingin-a-digital-world--from-vulnerable-to-valuable.pdf

Ipsos MORI. (2020). The Centre for Ageing Better. The experience of people approaching later life in lockdown: The impact of COVID-19 on 50-70-year olds in England. Centre for Ageing Better, London, United Kingdom. https://www. ageing-better.org.uk/publications/experience-people-approachinglater-lifelockdown-impact-covid-19-50-70-year-olds

Mercken, C. (2010). Education in an ageing society. Odyssee, Baarn, Netherlands.

Midwinter, E. (1984). Universities of the Third Age: English version. In: Midwinter, E. (ed), Mutual aid universities, Croom Helm Limited, Kent, United Kingdom, p. 3-19.

Moreira, T. (2016). Science, technology and the ageing society. Routledge, London, 2016.

National Statistics Office (2020). Regional statistics Malta. National Statistics sOffice, Malta, 2020.

Previtali, F., Allen, L.D., Varlamova, M. (2020). Not only virus spread: The diffusion of ageism during the outbreak of COVID-19. Journal of Aging \& Social Policy, 32 (4-5), p. 506-514.

Swindell, R.F. (2000). U3A without walls: Using the internet to reach out isolated people. Education and Ageing, 15 (2), p. 251-263

Swindell, R.F. (2002). U3A online: A virtual university of the third age for isolated older people. International Journal of Lifelong Education, 21 (5), p. 414-429.

Swindell, R.F., Vasella, K. (1999). Older learners online: An evaluation of Internet courses for isolated older persons. Griffith University, Brisbane, Australia.

Swindell, R.F., Grimbeek, P., Heffernan, J. (2011). U3A Online and successful aging: A smart way to help bridge the grey digital divide. In: Soar, J., Swindell, R.F., Tsang, P. (eds), Intelligent technologies for bridging the grey digital divide. Information Science Reference, New York, p. 122-140. 